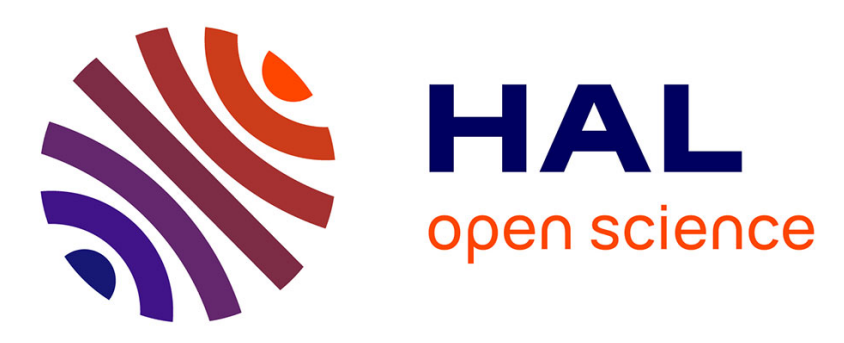

\title{
European heatwave in July 2006: Observations and modeling showing how local processes amplify conducive large-scale conditions
}

\author{
Marjolaine Chiriaco, Sophie Bastin, Pascal Yiou, Martial Haeffelin, \\ Jean-Charles Dupont, Marc Stéfanon
}

\section{To cite this version:}

Marjolaine Chiriaco, Sophie Bastin, Pascal Yiou, Martial Haeffelin, Jean-Charles Dupont, et al.. European heatwave in July 2006: Observations and modeling showing how local processes amplify conducive large-scale conditions. Geophysical Research Letters, 2014, 41 (15), pp.5644-5652. 10.1002/2014GL060205 . hal-01027438

\section{HAL Id: hal-01027438 \\ https://hal.science/hal-01027438}

Submitted on 30 Nov 2016

HAL is a multi-disciplinary open access archive for the deposit and dissemination of scientific research documents, whether they are published or not. The documents may come from teaching and research institutions in France or abroad, or from public or private research centers.
L'archive ouverte pluridisciplinaire HAL, est destinée au dépôt et à la diffusion de documents scientifiques de niveau recherche, publiés ou non, émanant des établissements d'enseignement et de recherche français ou étrangers, des laboratoires publics ou privés. 


\section{Geophysical Research Letters}

\section{RESEARCH LETTER}

10.1002/2014GL060205

Key Point:

- Heatwave can be studied in a precise location

Correspondence to:

M. Chiriaco,

Marjolaine.Chiriaco@latmos.ipsl.fr

\section{Citation:}

Chiriaco, M., S. Bastin, P. Yiou, M. Haeffelin, J.-C. Dupont, and M. Stéfanon (2014),

European heatwave in July 2006: Observations and modeling showing how local processes amplify conducive large-scale conditions, Geophys. Res. Lett., 41, 5644-5652, doi:10.1002/ 2014GL060205.

Received 11 APR 2014 Accepted 14 JUL 2014 Accepted article online 18 JUL 2014 Published online 4 AUG 2014

\section{European heatwave in July 2006: Observations and modeling showing how local processes amplify conducive large-scale conditions}

\author{
Marjolaine Chiriaco ${ }^{1}$, Sophie Bastin ${ }^{1}$, Pascal Yiou ${ }^{2}$, Martial Haeffelin ${ }^{3}$, Jean-Charles Dupont ${ }^{4}$, \\ and Marc Stéfanon ${ }^{5}$
}

${ }^{1}$ LATMOS-IPSL, Université Versailles St-Quentin, Sorbonne Universités, UPMC Université Paris 6, CNRS/INSU, Guyancourt, France, ${ }^{2}$ Laboratoire des Sciences du Climat et de I'Environnement, UMR 8272, CEA-CNRS-UVSQ, Gif-sur-Yvette CEDEX, France, ${ }^{3}$ Institut Pierre-Simon Laplace, FR636 Centre National de la Recherche Scientifique, Ecole Polytechnique, Palaiseau, France, ${ }^{4}$ Institut Pierre-Simon Laplace, FR636 Centre National de la Recherche Scientifique, Université Versailles St-Quentin, Guyancourt, France, ${ }^{5}$ ESE Laboratoire d'Écologie, Systématique et Évolution, CNRS/UPSUD, Orsay, France

\section{Introduction}

Western European climate is strongly influenced by the large-scale atmospheric circulation. In winter and summer, four regimes of circulations can be distinguished that lead to different regional climate conditions of regional climate [Cassou et al., 2005, 2011]. This implies that most of the low-frequency trends in surface pressure in the North Atlantic (during the last 50 years) are related to changes in the occurrence of those regimes. Hurrell [1995] found decadal trends in the North Atlantic Oscillation (NAO) that affect regional temperature at $2 \mathrm{~m}\left(T_{2 \mathrm{~m}}\right)$ and precipitation. Hurrell et al. [2004] have shown that the frequency of occurrence of the positive phase of the NAOfavoring anticyclonic weather over southern and central Europe-has increased at the end of the 20th century before it decreased in the first decade of the 21 st century. Moreover, for the same period, several studies [e.g., Corti et al., 1999; Coppola et al., 2005; Philipp et al., 2007] have shown that the main component in surface temperature warming in Europe is a reorganization of atmospheric circulations.

In the global warming context, the frequency and intensity of summer heatwaves are expected to increase in the coming years [Beniston, 2004; Meehl and Tebaldi, 2004], especially in Europe. The impact of extreme events, like the heatwave of the summer 2003 on economic activities and public health [World Health Organization, 2003], makes their understanding and forecasting a significant challenge for both scientific and policy-maker communities. Previous studies [Miralles et al., 2014 among others] have shown that the development of summer heatwaves, and their frequency and intensity, results from a combination of specific large-scale atmospheric circulations and specific land-atmosphere interactions:

1. To induce hot temperatures in central Europe, a quasi stationary anticyclonic circulation is required. It produces subsidence and warm-air advection [Fischer et al., 2007]. This induces high temperature collocalized with fair weather and high pressure [Stefanon et al., 2012]. Warm Atlantic [Sutton and Hodson, 2005; Della-Marta et al., 2007] and/or Mediterranean [Feudale and Shukla, 2007] sea surface temperatures also favor warm weather regime excitation in summer.

2. Soil moisture/precipitation feedback: Schär et al. [1999] have proposed a causal chain for the precipitation deficit, starting with a dry soil, which leads to an evapotranspiration deficit and further to reduced latent heat flux, 
cloud deficit, hot soil, more sensible heat flux, and higher surface temperature. This scheme has already been revisited by Fischer et al. [2007] and Vautard et al. [2007]. The deficit of precipitation occurs with an offset in time and space: around Mediterranean area and during winter and spring that precede warm summers. This lack of precipitation leads to an increase of sensible heat flux [Stegehuis et al., 2012] for heatwaves in western and eastern Europe only [Stefanon et al., 2012]. The crucial role of the partitioning between latent and sensible heat fluxes (controlled by soil moisture in most of Europe) was highlighted by Fischer et al. [2012].

This study focuses on the July 2006 heatwave in France. It aims to describe the role of the atmospheric circulation, the role of clouds, and the local role of soil moisture as heatwave ingredients, which are mentioned above. Most of the previous studies are based on regional simulations and/or statistical analysis. However, Vautard et al. [2013] pointed out that regional models have limited skill to simulate heatwaves, even at high resolution. Stegehuis et al. [2012] showed that regional models overestimate the latent heat flux and hence the soil moisture deficit over Europe in summer, which are the key parameters for heatwaves. Boé and Terray [2013] analyzed the evolution of soil-atmosphere interactions and cloud-temperature correlations in future climate projections. The predicted evolution of each process strongly depends on the way models simulate it in present-day conditions. If a model contains a bias in present climate, this bias tends to be amplified in future. Hence, it is important to characterize the relative importance of each process using observations. In this study, we use advanced observations and simulations (section 2) for the case of the July 2006 heatwave in Europe particularly in France. This heatwave was identified by Stefanon et al. [2012] and by Barriopedro et al. [2011] and studied for the specific case of England by Eden [2006], Galvin [2006], and Prior and Beswick [2006]. Observations are obtained from the SIRTA (Site Instrumental de Recherche par Télédétection Atmosphérique) reanalyses [Cheruy et al., 2012]. These reanalyses provide hourly averages of more than 40 variables from 2002. Satellite observations come from CALIPSO-GOCCPs (global climate model (GCM)-Oriented CALIPSO Cloud Products) [Chepfer et al., 2008, 2010], which provide cloud vertical detection at a larger scale than just the supersite. Twenty years of simulations from the Weather Research and Forecast (WRF) mesoscale model complete these data sets. In order to understand the implication of soil moisture in the heatwave, two simulations are used, including one which does not produce any soil moisture deficit. Observations and simulations are analyzed using the flow analog method [Yiou et al., 2007]. It allows us to separate large-scale circulation variability from other sources of variability. The results and the discussion, in sections 3 and 4, respectively, show that the specific tools used in this study allow us to identify the role of the large-scale component in the heatwave (inducing clear sky) and the role of the local processes that amplify it (dry soil pattern).

\section{Tools and Method}

This study is mainly based on observations collected at the SIRTA atmospheric observatory, located $20 \mathrm{~km}$ southwest of Paris $\left(2.2^{\circ} \mathrm{E} / 48.7^{\circ} \mathrm{N}-160 \mathrm{~m}\right.$ of altitude), from 2003 to 2011 [Haeffelin et al., 2005]. This observatory has collected many observations since 2002, which are now synthesized into the so-called "SIRTA Reanalysis data set" as described by Cheruy et al. [2012]. After many steps of data quality control and harmonization [Cheruy et al., 2012], the "SIRTA Reanalysis" file contains hourly averages of more than 40 variables at this site. Unfortunately, there are not enough available data for latent heat fluxes, and therefore, these variables cannot be used in this study. Clear-sky longwave/shortwave downwelling radiative flux rldscs/rsdscs are estimated from Long and Ackerman [2000]. The clear-sky fluxes are subtracted from the total measured downwelling radiative flux, longwave ( $r l d s)$ and shortwave (rsds), at the surface to get the cloud radiative forcing (CRF):

$$
\begin{gathered}
\mathrm{CRF}_{\mathrm{LW}}=r l d s-r l d s c s \\
\mathrm{CRF}_{\mathrm{SW}}=|r s d s-r s d s c s|
\end{gathered}
$$

$\mathrm{CRF}_{\mathrm{LW}}$ (equation (1)) quantifies the cloud greenhouse effect, which is always positive. $\mathrm{CRF}_{\mathrm{SW}}$ (equation (2)) is a quantification of their albedo effect (nonzero only during day) and thus represents the cooling effect of clouds. The absolute value is applied to $\mathrm{CRF}_{\mathrm{SW}}$ in order to get positive values when clouds are present. In the following, all CRF $\mathrm{LW}_{\mathrm{LW}}$ values are considered (day and night), whereas only the daytime ones are kept for $\mathrm{CRF}_{\mathrm{SW}}$. The percentage of hole in the data, estimated over the period of existing instrument, are $13 \%$ for $r l d s c s$ and $r s d s c s$ and $4 \%$ for $r l d s$ and $r s d s$.

Low-altitude cloud fraction (CF), from GOCCP (GCM Oriented CALIPSO Cloud Product) [Chepfer et al., 2008, 2010], is used in order to get large-scale cloud information. This low-altitude cloud (under $3.2 \mathrm{~km}$ of altitude) product is based on spaceborne lidar measurements and is extracted over Europe in a $2^{\circ} \times 2^{\circ}$ horizontal grid. GOCCP data are available for each month of July from 2006 to 2012. 

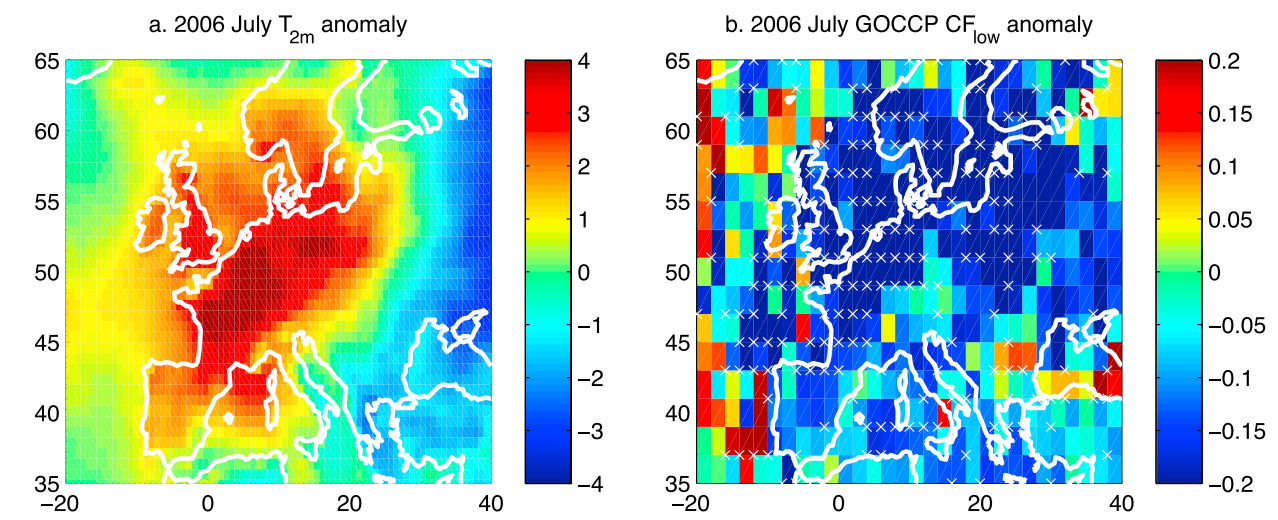

Figure 1. The July 2006 monthly anomaly compared to the July 2006-2012 mean values: (a) For ERA-I $T_{2} \mathrm{~m}$. (b) For the low-cloud fraction from GOCCP $\left(2^{\circ} \times 2^{\circ} \mathrm{grid}\right)$. Anomaly values above $1 \sigma$ are identified by a white mark.

Simulations from WRF mesoscale model complete these observations to better identify the dynamical processes. The model is useful for the surface-atmosphere feedback, which contribute locally to the temperature anomaly. Two 20 year simulations were performed at $20 \mathrm{~km}$ resolution over the Mediterranean Basin in the framework of CORDEX (COordinated Downscaling Experiment) [Giorgi et al., 2009]. Note that MED-CORDEX is the Mediterranean focus of CORDEX. The two simulations perform a dynamical downscaling of the ERA-Interim data [Simons et al., 2007]. Both simulations use the same set of parameterizations, except for the surface scheme. In one of the simulations (hereafter called Rapid Update Cycle (RUC)), soil moisture can evolve freely by using the sophisticated Rapid Update Cycle (RUC) land surface model [Smirnova et al., 1997, 2000]. This simulation is used as it is physically more realistic, and outputs are available until 2011. In the other simulation (called DIFfusive (DIF), details on the simulations configuration can be found in Stefanon et al. [2014]), the soil moisture availability is prescribed and set to climatological wintertime value preventing any soil moisture deficit condition. This simulation is only used at the end of the paper to evaluate the importance of surface conditions. This second simulation ends in 2008 , so we computed another set of analogs covering a longer period (1989-2008, i.e., the common period of availability of simulations). These two simulations were not specifically designed for this study but were produced in the framework of the MED-CORDEX intercomparison exercise. Here we show that we can take advantage of these simulations to consider two different situations: one where soil moisture is limited (RUC) and the other one where it is not. It will not allow us to quantify precisely the impact of soil moisture on temperature anomaly but to discriminate its impact to other conditions.

We want to determine whether the different variable (temperature, cloud variables, and surface variables) anomalies are explained by the large-scale circulation variability. For that, the method of circulation analogs [Yiou et al., 2007; Cattiaux et al., 2009] is applied to the two databases of sea level pressure (SLP) (observations and simulations). For each D day of July between 2003 and 2012, 10 flow analogs are selected among all the days from the beginning of 2003 to the end of 2012. The dates are selected by maximizing the Spearman correlation of the daily SLP maps $\left(25.5^{\circ} \mathrm{N}<\right.$ latitude $<70.5^{\circ} \mathrm{N}$ and $60^{\circ} \mathrm{W}<$ longitude $\left.<49.5^{\circ} \mathrm{E}\right)$, provided that they are no closer than 8 days from the day $D$, in order to keep meteorologically independent estimates. In the following results, from all analogs identified with this procedure, only analogs with correlation coefficient larger than 0.5 are considered (about $80 \%$ of the analogs). In July, 100\% of the analogs are found between May and September (and about $90 \%$ between June and August). Minimizing a Euclidian distance rather than maximizing the Spearman correlation shows a very similar results (the same dates are most of the time selected), as in Cattiaux et al. [2009]. Vautard and Yiou [2009] have also shown that changing the size and the location of the maps, as well as the large-scale variable $(700 \mathrm{hPa}$ wind instead of SLP), do not change the results qualitatively.

Thereafter, the term "anomaly" exclusively corresponds to the difference between the value of a variable (daily or monthly) and the same variable averaged over several years (2002-2012 most of the time).

\section{Results}

The heatwave that we are interested in occurs in July 2006 over western Europe (Figure 1a); this heatwave is characterized by some variability of amplitude. The monthly $2 \mathrm{~m}$ temperature $\left(T_{2 \mathrm{~m}}\right)$ mean is about 4 to $5^{\circ} \mathrm{C}$ 

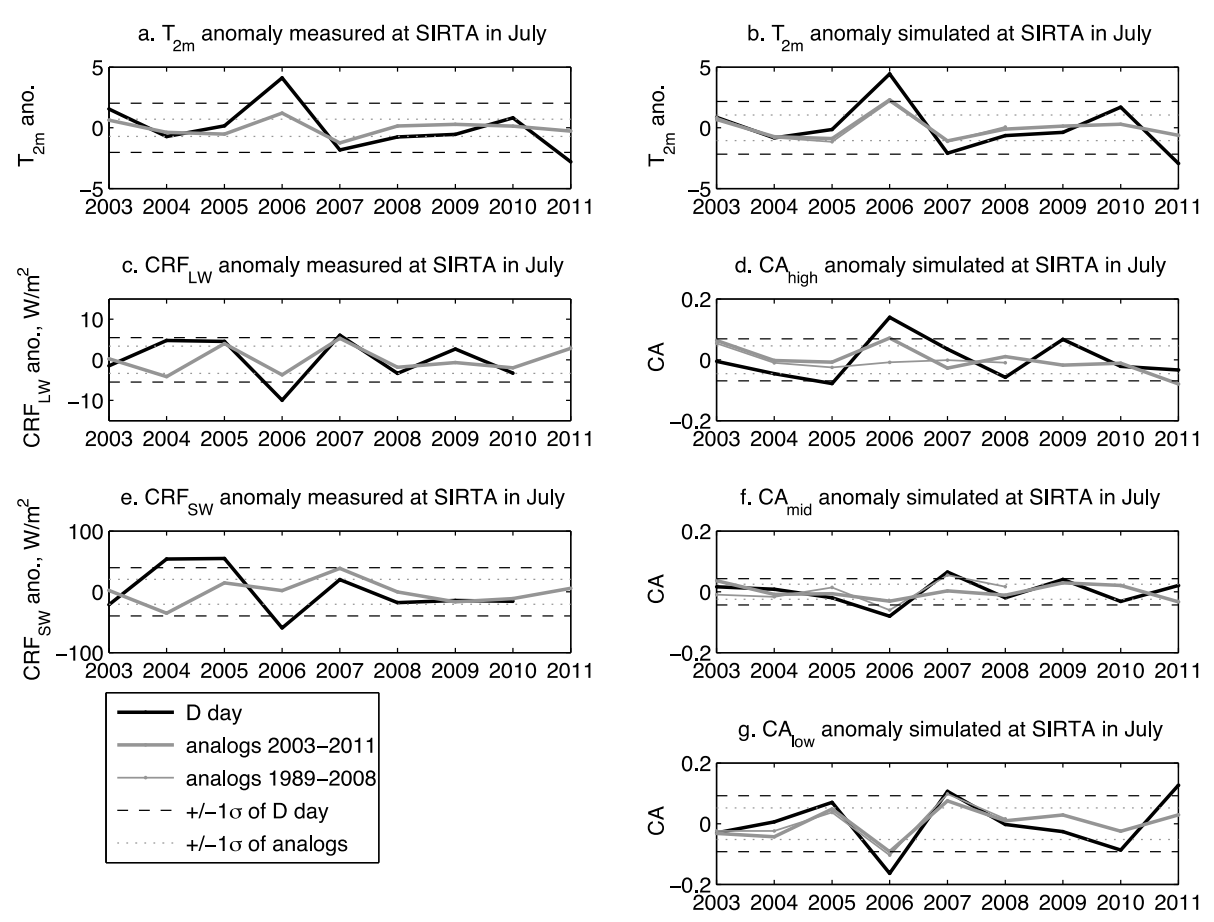

Figure 2. The July monthly anomaly compared to 2003-2011 for (a) $T_{2} \mathrm{~m}$ measured at SIRTA, (b) same as in Figure 2a but for the simulations, (c) LW cloud radiative forcing measured at SIRTA, (d) the high cloud amount in the simulations, (e) same as in Figure $2 \mathrm{c}$ but for the SW one (absolute value), (f) same as in Figure $2 \mathrm{~d}$ but for the midclouds, and (g) same as in Figure $2 \mathrm{~d}$ but for the low-altitude clouds. D days are in black line and the 10 analogs in grey line; the dashed (respectively, dotted) horizontal lines are the $\pm 1 \sigma$ values of the $D$ day (respectively, analog) anomalies. In Figures $2 b, 2 d, 2 f$, and $2 \mathrm{~g}$, the analogs calculated from the 1989-2008 simulation have been added (fine grey line).

warmer than the average value of the months of July from 2006 to 2012 over France. It is $3^{\circ} \mathrm{C}$ warmer over southern England and $2^{\circ} \mathrm{C}$ warmer above ocean and Scandinavia. The anomaly derived with respect to the July 2002 to 2012 average shows similar magnitude. The summer of 2006 is also categorized as a heatwave by Barriopedro et al. [2011] and Stefanon et al. [2012]. The low-altitude CF anomaly, represented in Figure 1b, is the difference between the July 2006 low-altitude CF and the 2006-2012 average July monthly mean low-altitude CF of GOCCP maps. The observed pattern of low-altitude CF anomaly is very similar to $T_{2} \mathrm{~m}$, with an important low-altitude cloud deficit over the western part of Europe. Unlike $T_{2 \mathrm{~m}}$, there is no distinction between land and ocean for low-altitude CF. Previous studies about the circulation conditions during this month [Eden, 2006; Galvin, 2006; Prior and Beswick, 2006] have shown that the mean monthly SLP is above normal over Europe during this month. They have also shown that the air which is advected above France comes from the northeastern part of Europe (i.e., dry air). To summarize, the heatwave is correlated to low-altitude cloud deficit, consistently with the direction of air circulation, and is more important over land.

The July 2006 heatwave is detected at the SIRTA observatory (Figure 2a). The monthly mean of $T_{2 \mathrm{~m}}$ is about $4.5^{\circ} \mathrm{C}$ warmer than its average value from 2003 to 2012 and about $2^{\circ} \mathrm{C}$ above $1 \sigma$ (still $0.3^{\circ} \mathrm{C}$ above $2 \sigma$ ). As shown in Figure 2a, this positive anomaly at SIRTA is also detected for the mean value of analogs but with a weaker amplitude, as it does not exceed $1 \sigma$ of the analogs. This result confirms that the large-scale circulation conditions only explain a fraction of the temperature positive anomaly in July 2006 . Figure $2 b$ shows similar results for the RUC simulation. This heatwave is associated with an important deficit in the measured cloud radiative forcing for both LW and SW, represented in Figure $2 c$ and 2e, respectively. This negative anomaly is also more important than in the analogs, especially in the SW. Both greenhouse and albedo effects are then weaker than what is expected for similar large-scale circulation conditions, based on analogs, on average. This result is consistent with the simulation, as we can see that low-altitude clouds represented in Figure $2 \mathrm{~g}$ are less frequent in July 2006 than in other July months, and still less frequent than for the circulation analogs.

The monthly difference between $T_{2 \mathrm{~m}}$ in July 2006 (hereafter D-day $T_{2 \mathrm{~m}}$ ) and analogs $T_{2 \mathrm{~m}}$ is concentrated in a few days (from 15 July to 27 July 2006) for both measurements (Figure 3a) and simulation (Figure 3b). 

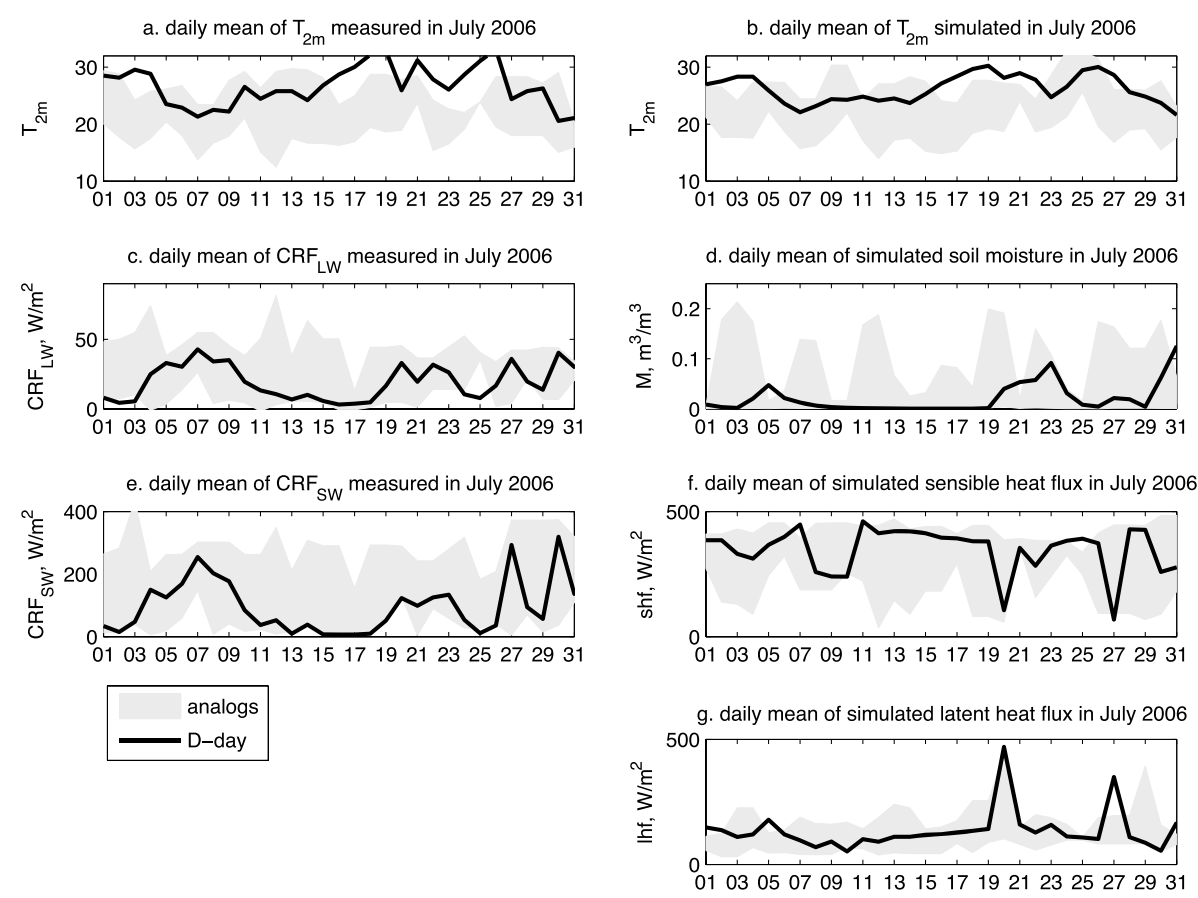

Figure 3. Variability of the daily values in July 2006 for (a) $T_{2} m$ measured at SIRTA, (b) same as in Figure 3a but for the simulations, (c) the LW cloud radiative forcing measured at SIRTA, (d) the simulated soil moisture, (e) same as in Figure $3 c$ but for the SW one (absolute value), ( $\mathrm{f}$ ) the simulated sensible heat flux, and (g) same as in Figure $3 \mathrm{f}$ but for the latent one. $\mathrm{D}$ days are in black line and the 10 analogs in grey area.

During the first 3 days of this heatwave, both LW (Figure 3c) and SW (Figure 3e) CRF are almost zero. It corresponds to clear-sky conditions. From 19 July, both CRF increase, but the SW CRF remains weak, revealing a cloud deficit during this period. Figures $4 \mathrm{a}-4 \mathrm{~d}$ and $4 \mathrm{f}$ confirms the results of the simulation, suggesting that the deficit in CRF is due to an absence of cloud. This cloud deficit is observed based on lidar measurements and MSG (Meteosat Second Generation) cloud products derived from the imager and radiometer onboard [Roebeling et al., 2006, 2008]. Lidar profiles from 15 to 27 July (Figure 4a) show a persistent clear-sky condition, where the yellow color corresponds to aerosols only in the boundary layer, whereas the orange and red colors show the presence of the clouds. For instance, on 17 July, the sky was completely clear (Figure 4a). These clouds are also missing around SIRTA, as shown by the MSG CF product (Figure 4f) average values of the $15 \times 15$ pixels (i.e., $15 \times 15 \mathrm{~km}^{2}$ ) over SIRTA. In the analog curves of this CF product, an important daily cycle appears. The clouds missing until 20 July could be low-altitude clouds, mainly driven by the boundary layer. From 20 to 23 July, some high clouds are present in the lidar profiles (Figure 4a) and by the large values of $\mathrm{CRF}_{\mathrm{LW}}$ (Figure 4b). Some low-altitude clouds also appear as shown by some hours with important albedo effects (Figure 4d). After 23 July, three nearly cloud-free days are observed. Finally, new clouds are present on 27 July and are associated with lower $T_{2 \mathrm{~m}}$.

In addition to this lack of clouds, the soil is very dry (Figure 3d) and even drier than in the analogs. The dryness of the soil is visible 6 days before the heatwave occurs. It induces an excess of sensible heat flux (around $250 \mathrm{~W} \mathrm{~m}^{-2}$; Figure $3 \mathrm{f}$ ), which generates an accumulation of heat in the lower layers. Chronologically, from 13 to 18 July, there is both a dry soil and a CRF deficit due to absence of low clouds. $T_{2} \mathrm{~m}$ increases, becoming warmer than in analogs from 15 July $\left(25^{\circ} \mathrm{C}\right.$ for D day against $22^{\circ} \mathrm{C}$ for the analogs). From 19 to 23 July, clouds appear, and the topsoil layer is more moist due to precipitation. $T_{2 \mathrm{~m}}$ decreases somewhat to reach $23^{\circ} \mathrm{C}$. The temperature increases again between 24 and 26 July, when cloud occurrences decrease and the soil becomes dry again. To summarize, the heatwave, which is detected in the monthly mean, is explained by a few days, which are warmer than expected for similar large-scale circulation conditions. Possibilities to explain the positive temperature anomaly could be either a deficit of low-altitude clouds, or a soil, which is dry several days before, or both effects with or without interconnections. The question of the combination of these drivers is addressed in the following discussion. 

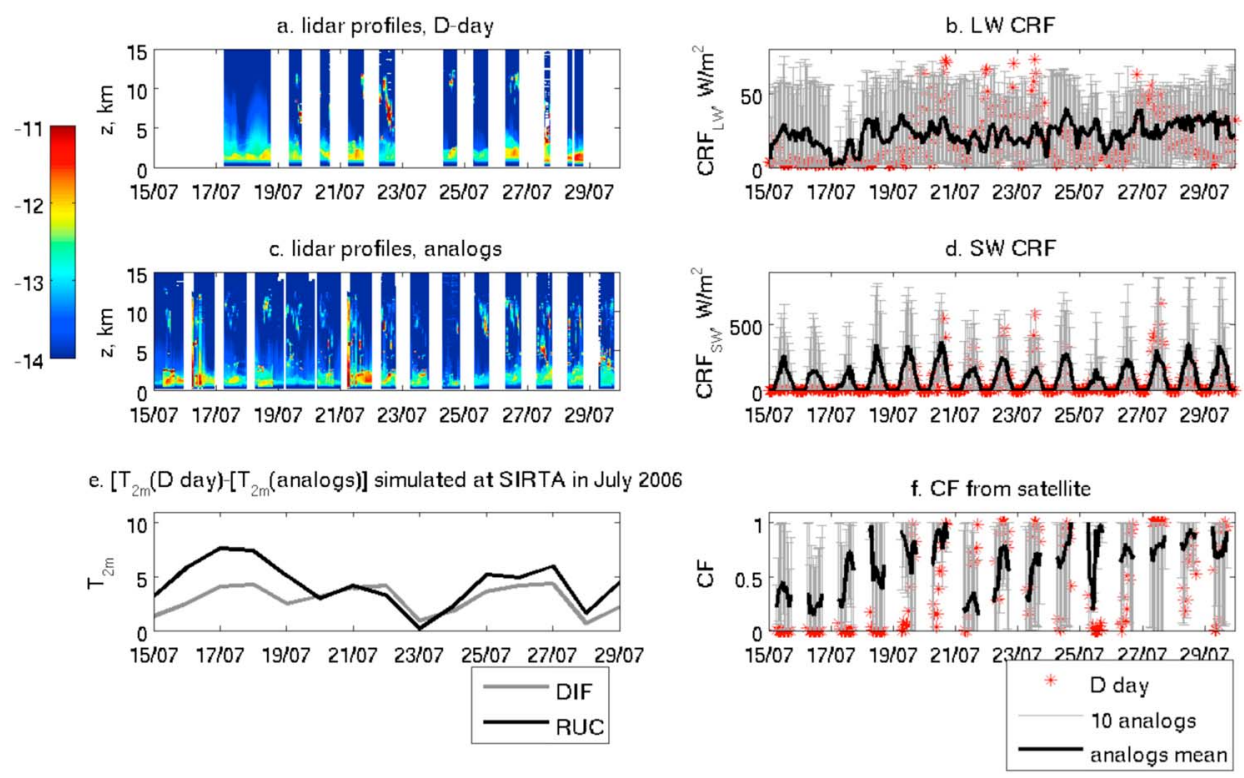

Figure 4. From 15 July to 29 July: (a) hourly mean of log of lidar signal (color bar is log(ATB) where ATB is the attenuated backscattered signal) for D days measured at SIRTA, (b) hourly mean of LW CRF measured at SIRTA for the D days (red stars) and the analogs (black line for the mean of the 10 analogs, and grey bars for the total range of the 10 analogs), (c) same as in Figure 4a but for the analogs - on averaged, 2.5 days of analogs have lidar data, (d) same as in Figure $4 \mathrm{~b}$ but for the SW CRF, and (e) difference between the $2 \mathrm{~m}$ temperature of the $\mathrm{D}$ days and the mean $2 \mathrm{~m}$ temperature of the 10 analogs for the simulation with RUC surface scheme (black line) and for the simulation DIF with the thermal diffusive scheme (grey line), daily means. From 15 to 19 July, the 10 analogs have a score above 0.5 ; from 20 to 29 July, the 6 analogs on averaged have a score above 0.5 .

\section{Discussion and Conclusion}

July 2006 is very warm compared to other July months in the same decade. This heatwave is not only explained by the large-scale circulation conditions, especially from 15 to 27 July. However, a "blocking" weather regime is found from the beginning of the heatwave to 20 July (regime 2 shown in Figure A1) and an Atlantic low weather regime occurs from 21 July (regime 4 in Figure A1). According to Cassou et al. [2005], these two regimes promote heatwaves. The analogs are in the same weather regime. Nevertheless, the difference between the D-day $T_{2 m}$ and the analog $T_{2 m}$ indicates that the clustering in this weather regime alone cannot explain the magnitude of the heatwave. The July 2006 heatwave represents an extreme of the Scandinavia-western Europe regime. The persistence of this particular regime could explain why a monthly anomaly is detected. Nevertheless, it does not explain the magnitude of the daily anomaly (during both day and night-not shown).

This heatwave is associated with a deficit of low-altitude clouds and a very dry soil according to the WRF model. Soil dryness and large-scale conditions are thus two concomitant parameters. To understand if there is a specific link between them that could explain the July 2006 heatwave, we use the second simulation (DIF) in which the soil moisture deficit is not created (the soil moisture is prescribed based on a winter value). In the DIF simulation, the difference between D day and analogs explains and likely exaggerates a little (as it is a wintertime value) the part of $T_{2 \mathrm{~m}}$ anomaly due to large-scale circulation conditions. Then, the significant difference between RUC and DIF simulations suggests that the part of $T_{2 \mathrm{~m}}$ anomaly, which is due to the soil dryness, can reach several degrees. Almost all along the heatwave, the $D$-day $T_{2 m}$ is warmer than the analog value for both surface model schemes (RUC one or DIF one; Figure 4e). The difference between D-day $T_{2 \mathrm{~m}}$ and analog $T_{2 \mathrm{~m}}$ is larger for the RUC simulation than for the DIF simulation in the first part of the heatwave (i.e., reaching $8^{\circ} \mathrm{C}$ for RUC and only $4^{\circ} \mathrm{C}$ for DIF from 15 July to 19 July). The differences are then equivalent in the two simulations during the rest of the heatwave (i.e., from 20 July to 28 July). This means that the dry soil contributes to amplify the $T_{2 \mathrm{~m}}$ anomaly in the first 5 days of the heatwave only, during the blocking weather regime. When the regime becomes an Atlantic low weather regime, it becomes sufficient to explain the magnitude of the temperature anomaly. There are no significant differences in cloudiness (low-altitude and midaltitude clouds) between dry soil (RUC) and moist soil (DIF) conditions (not shown). Hence, the dry soil is not responsible for the deficit of low-altitude clouds, but it can contribute to amplify the cloud deficit. Moreover, 
Figure $1 \mathrm{~b}$ shows that the horizontal extent of low-altitude cloud deficit is important and occurs over ocean as well as over land.

This study based on advanced ground and spaceborne observations confirms the different conditions required for some specific heatwaves (described in section 1), when the atmospheric circulation alone cannot explain the amplitude of the heatwave, including the offset in space (southern) and time (previous season) of the precipitation deficit (from CRU, not shown).

We show how the combination of long-term observations and simulations may help to better understand extreme events. Indeed, Vautard et al. [2013] have shown that even at high resolution, regional climate models have difficulties to represent heatwaves. Also, Boé and Terray [2013] have shown that the importance of one process in comparison with others is different from one model to another: therefore, it is difficult to use only models to explain the mechanisms induced in such events. On the contrary, observations are often incomplete or difficult to use in synergy. The long-term observation efforts that have been carried out at the SIRTA observatory and at other sites are thus very useful and important for climate communities.

\section{Appendix A: North Atlantic Weather Regimes in Summer}

Figure A1 shows the four North Atlantic weather regimes in Summer, computed from NCEP sea level pressure reanalysis (1948-2013). These regimes are obtained using a k-means algorithm following Yiou et al. [2008]. In this figure regime 1 is NAO-, regime 2 is the blocking, regime 3 is NAO+, and regime 4 is the Atlantic Low.
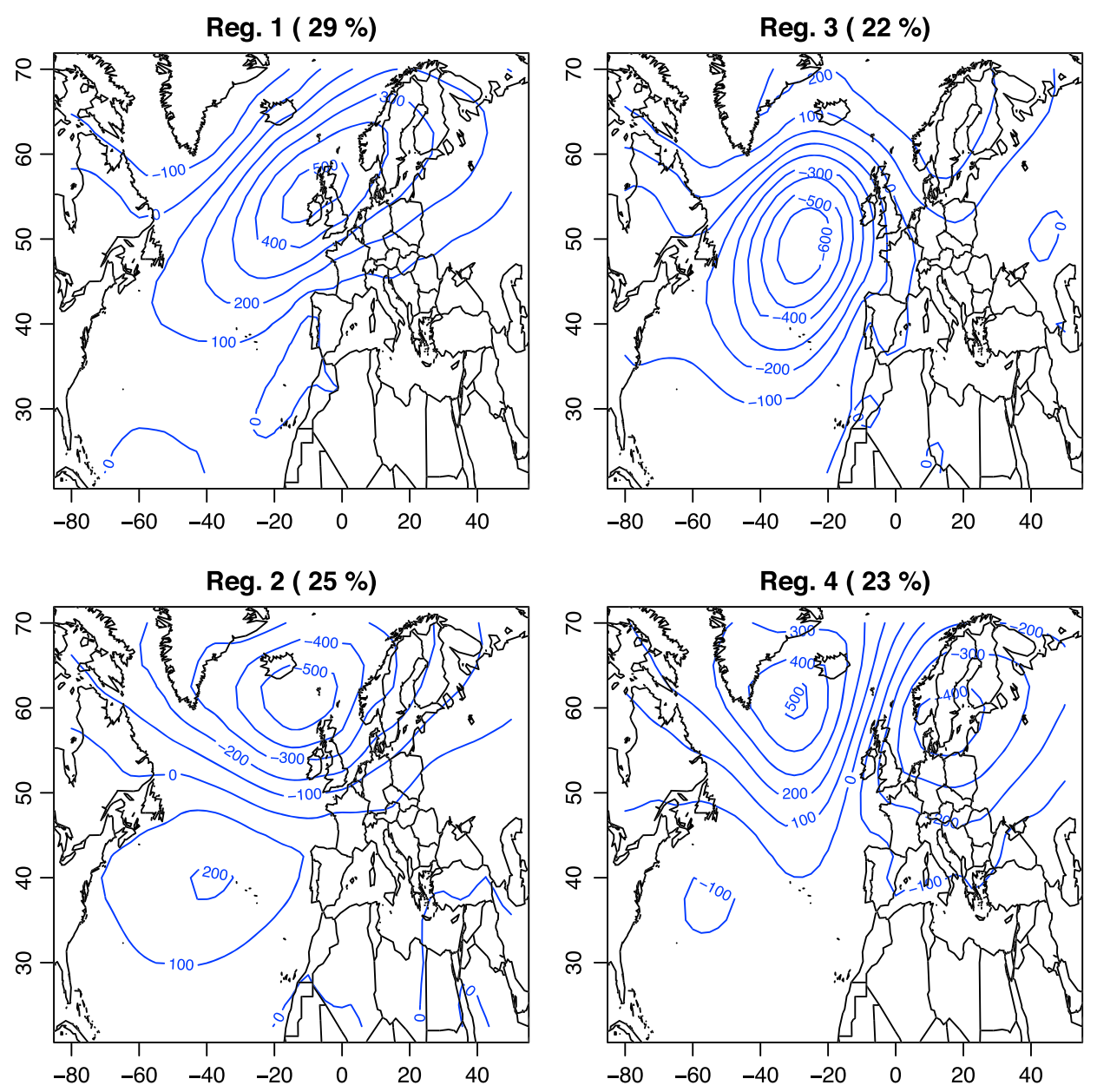

Figure A1. Summer (June-July-August) North Atlantic weather regimes computed on the SLP from National Centers for Environmental Prediction reanalysis (1948-2013). The weather regimes were determined on seasonal anomalies of SLP. We used a $k$-mean algorithm with the procedure of Yiou et al. [2008]. The isolines show the SLP anomalies in pascal. The average frequencies of the regimes are indicated in percent sign. 
Acknowledgments

We acknowledge (i) Julien Delanoë for the internal review of the paper and (ii) the Cloudnet project (European Union contract EVK2-2000-00611) for providing the METEOSAT cloud physical properties data set, which was produced by the Royal Netherlands Meteorological Institute (KNMI)]. (iii) This work is a contribution to the HYdrological cycle in The Mediterranean EXperiment program through INSUMISTRALS support and the Med-CORDEX program (COordinated Regional climate Downscaling EXperiment Mediterranean region), with granted access to the HPC resources of IDRIS (under allocation i2011010227); (iv) the SIRTA and Climserv teams at IPSL for collecting and providing data and computing ressources; (v) Cindy Lebeaupin-Brossier for providing one of the simulation outputs; and (vi) the CNES for partially founded M. Chiriaco research. We also thank Helene Freville, Julien Cattiaux, Helene Chepfer, Philippe Drobinski, and Vincent Noel for their fruitful discussions. $P$ Yiou is supported by the ERC grant 338965-A2C2.

The Editor thanks an anonymous reviewer for assisting in the evaluation of this paper.

\section{References}

Barriopedro, D., E. M. Fischer, J. Luterbacher, R. M. Trigo, and R. Garcia-Herrera (2011), The hot summer of 2010: Redrawing the temperature record map of Europe, Science, 332, 220-224.

Beniston, M. (2004), The 2003 heat wave in Europe. A shape of things to come?, Geophys. Res. Lett, 31, L02022, doi:10.1029/2003GL018857. Boé, J., and L. Terray (2013), Land-sea contrast, soil-atmosphere and cloud-temperature interactions: Interplays and roles in future summer European climate change, Clim. Dyn., 42, 683-699.

Cassou, C., L. Terray, and A. S. Phillips (2005), Tropical Atlantic influence on European heat waves, J. Clim., 18, $2805-2811$.

Cassou, C., M. Minvielle, L. Terray, and C. Perigaud (2011), A statistical-dynamical scheme for reconstructing ocean forcing in the Atlantic. Part I: Weather regimes as predictors for ocean surface variables, Clim. Dyn., 36, 19-39.

Cattiaux, J., R. Vautard, and P. Yiou (2009), Origins of the extremely warm European fall of 2006, Geophys. Res. Lett., 36, L06713, doi:10.1029/ 2009GL037339.

Chepfer H., S. Bony, D. M. Winker, M. Chiriaco, J.-L. Dufresne, and G. Seze (2008), Use of CALIPSO lidar observations to evaluate the cloudiness simulated by a climate model, Geophys. Res. Lett., 35, L15704, doi:10.1029/2008GL034207.

Chepfer, H., S. Bony, D. M. Winker, G. Cesana, J. L. Dufresne, P. Minnis, C. J. Stubenrauch, and S. Zeng (2010), The GCM Oriented CALIPSO Cloud Product (CALIPSO-GOCCP), J. Geophys. Res., 105, D00H16, doi:10.1029/2009JD012251.

Cheruy, F., J. C. Dupont, A. Campoy, A. Ducharne, F. Hourdin, M. Haeffelin, and M. Chiriaco (2012), Combined influence of atmospheric physics and soil hydrology on the realism of the LMDz model compared to SIRTA measurements, Clim. Dyn., doi:10.1007/s00382-012-1469-y.

Coppola, E., F. Kucharski, F. Giorgi, and F. Molteni (2005), Bimodality of the North Atlantic Oscillation in simulations with greenhouse gas forcing, Geophys. Res. Lett., 32, L23709, doi:10.1029/2005GL024080.

Corti, S., F. Molteni, and T. N. Palmer (1999), Signature of a recent climate change in frequencies of natural atmospheric circulation regimes, Nature, 398(6730), 799-802.

Della-Marta, P. M., J. Luterbacher, H. von Weissenfluh, E. Xoplaki, M. Brunet, and H. Waner (2007), Summer heat waves over western Europe 1880-2003, their relationship to large-scale forcings and predictability, Clim. Dyn., 29, 251-275.

Eden, P. (2006), Hottest and sunniest on record over much of the UK; thundery at times, Weather Log, 61(9), i-iv.

Feudale, L., and J. Shukla (2007), Role of Mediterranean SST in enhancing the European heat wave of summer 2003, Geophys. Res. Lett., 34, L03811, doi:10.1029/2006GL027991.

Fischer, E. M., S. I. Seneviratne, D. Lüthi, and C. Schär (2007), Contribution of land-atmosphere coupling to recent European summer heat waves, Geophys. Res. Lett., 34, L06707, doi:10.1029/2006GL029068.

Fischer, E. M., J. Rajczak, and C. Schär (2012), Changes in European summer temperature variability revisited, Geophys. Res. Lett., 39, L19702 doi:10.1029/2012GL052730

Galvin, J. F. P. (2006), Forecasting the record-breaking temperatures of mid-July 2006, Weather, 62(7), 186-190, doi:10.1002/wea.106.

Giorgi, F., C. Jones, and G. Asrar (2009), Addressing climate information needs at the regional level: The CORDEX framework, WMO Bull., 58 , $175-183$.

Haeffelin, M., et al. (2005), SIRTA, a ground-based atmospheric observatory for cloud and aerosol research, Ann. Geophys., 23, 253-275.

Hurrell, J. W. (1995), Decadal trends in the North Atlantic Oscillation: Regional temperatures and precipitation, Science, 269, 676-679, doi:10.1126/science.269.5224.676.

Hurrell, J. W., M. P. Hoerling, A. S. Philliphs, and T. Xu (2004), Twentieth century North Atlantic climate change. Part I: Assessing determinism, Clim. Dyn., 23, 371-389.

Long, C. N., and T. P. Ackerman (2000), Identification of clear skies from broadband pyranometer measurements and calculation of downwelling shortwave cloud effects, J. Geophys. Res., 105(D12), 15,609-15,626, doi:10.1029/2000JD900077.

Meehl, G. A., and C. Tebaldi (2004), More intense, more frequent, and longer lasting heat waves in the 21st century, Science, 305(5686), 994-997.

Miralles, D. G., A. J. Teuling, C. C. Van Heerwaarden, and J. Vila-Guérau de Arellano (2014), Mega-heatwave temperatures due to combined soil desiccation and atmospheric heat accumulation, Nat. Geosci., 7, 345-349.

Philipp, A., P. M. Della-Marta, J. Jacobeit, D. R. Fereday, P. D. Jones, A. Moberg, and H. Wanner (2007), Long term variability of daily North Atlantic-European pressure patterns since 1850 classified by simulated annealing clustering, J. Clim., 20(16), 4065-4095.

Prior, J., and M. Beswick (2006), The record-breaking heat and sunshine of July 2006, Weather, 62(7), 174-182, doi:10.1002/wea.101.

Roebeling, R. A., A. J. Feijt, and P. Stammes (2006), Cloud property retrievals for climate monitoring: Implications of differences between SEVIRI on METEOSAT-8 and AVHRR on NOAA-17, J. Geophys. Res., 111, D20210, doi:10.1029/2005JD006990.

Roebeling, R. A., H. M. Deneke, and A. J. Feijt (2008), Validation of cloud liquid water path retrievals from SEVIRI using one year of CloudNET observations, J. Appl. Meteorol. Climatol., 47, 206-222.

Schär, C., D. Lüthi, U. Beyerle, and E. Heise (1999), The soil-precipitation feedback: A process study with a regional climate model, J. Clim., 12, 722-741.

Simons, A., S. Uppala, D. Dee, and S. Kobayashi (2007), ERA-interim: New ECMWF reanalysis products from 1989 onwards, ECMWF Newsletter $110,25-35$.

Smirnova, T. G., J. M. Brown, and S. G. Benjamin (1997), Performance of different soil model configurations in simulating ground surface temperature and surface fluxes, Mon. Weather Rev., 125, 1870-1884.

Smirnova, T. G., J. M. Brown, S. G. Benjamin, and D. Kim (2000), Parameterization of cold season processes in the maps land-surface scheme, J. Geophys. Res., 105(D3), 4077-4086, doi:10.1029/1999JD901047.

Stefanon, M., F. D'Andrea, and P. Drobinski (2012), Heatwave classification over Europe and the Mediterranean region, Environ. Res. Lett., 7(1), 014023, doi:10.1088/1748-9326/7/1/014023.

Stefanon, M., P. Drobinski, F. D'Andrea, C. Lebeaupin-Brossier, and S. Bastin (2014), Soil moisture-temperature feedbacks at meso-scale during summer heat waves over Western Europe, Clim. Dyn., 42(5-6), 1309-1324, doi:10.1007/s00382-013-1794-9.

Stegehuis, A. I., R. Vautard, P. Ciais, A. J. Teuling, M. Jung, and P. Yiou (2012), Summer temperatures in Europe and land heat fluxes in observations-based data and regional climate model simulations, Clim. Dyn., 41, 455-477.

Sutton, R. T., and D. L. R. Hodson (2005), Atlantic Ocean forcing of North American and European summer climate, Science, 309, $115-118$.

Vautard, R., and P. Yiou (2009), Control of recent European surface climate by atmospheric flow, Geophys. Res. Lett., 36, L22702, doi:10.1029/2009GL040480.

Vautard, R., P. Yiou, F. D'Andrea, N. de Noblet, N. Viovy, C. Cassou, J. Polcher, P. Ciais, M. Kageyama, and Y. Fan (2007), Summertime European heat and drought waves induced by wintertime Mediterranean rainfall deficit, Geophys. Res. Lett., 34, L07711, doi:10.1029/2006GL028001.

Vautard, R., T. Noel, L. Li, M. Vrac, E. Martin, P. Dandin, J. Cattiaux, and S. Joussaume (2013), Climate variability and trends in downscaled highresolution simulations and projections over Metropolitan France, Clim. Dyn., doi:10.1007/s00382-012-1621-8. 
World Health Organization (2003), The health impacts of 2003 summer heat-waves: Briefing note for the delegations of the fifty-third session of the WHO regional committee for Europe, World Health Organization, Geneva, Switzerland.

Yiou, P., R. Vautard, P. Naveau, and C. Cassou (2007), Inconsistency between atmospheric dynamics and temperatures during the exceptional 2006/2007 fall/winter and recent warming in Europe, Geophys. Res. Lett., 34, L21808, doi:10.1029/2007GL031981.

Yiou, P., K. Goubanova, X. Z. Li, and M. Nogal (2008), Weather regime dependence of extreme value statistics for summer temperature and precipitation, Nonlin. Processes Geophys., 15, 365-378, doi:10.5194/npg-15-365-2008. 